\title{
ПРИМЕНЕНИЕ МЕТОДА
}

ФУНКЦИОНАЛЬНО-СТОИМОСТНОГО

АНАЛИЗА НА ЭТАПЕ РАЗРАБОТКИ ХЛЕБОБУЛОЧНЫХ ИЗДЕЛИЙ

\author{
Application of the Functional and Cost Analysis Method \\ on the Development Stage of the Bakery Products
}

\author{
Маюрникова Л.А., Уржумова А.И., Клишина М.Н. \\ Majurnikova L.A., Urzhumova A.I., Klishina M.N.
}

Ключевые слова:
функционально-
стоимостной анализ;
сдобные
хлебобулочные
изделия;
противоречия;
принятие решений;
пароконвектомат

Keywords:

functional and cost analysis; rich fermented bakery products; contradictions; making decisions; convection steamer

\section{Реферат}

Применение функционально-стоимостного анализа (ФСА) в машиностроении, приборостроении, энергетике и других отраслях промышленности демонстрирует высокую эффективность его результатов: происходит снижение стоимости производства, сокращение числа деталей, упрощение технологий производства при условии сохранения требуемого уровня качества. Особенно эффективен ФСА на этапе проектирования нового изделия, в том числе пищевого продукта.

Исследована возможность применения ФСА с целью сокращения затрат на производство сдобных хлебобулочных изделий социального значения, т. е. используемых для питания детей в детсадах и школах; данные продукты ежедневного потребления становится доступнее для потребителя. Граничными условиями являются: требования нормативно-технической документации на производство сдобных хлебобулочных изделий; материально-техническое оснащение; объем производства предприятия социального значения (школьное питание).

Типовая последовательность анализа учитывает особенности производства пищевого продукта - сдобного хлебобулочного изделия.

Проведено ранжирование функций изделия, описано соотношение «значимость - затраты» для каждой функции.

Каждое принятое конструкторское решение, помимо положительного эффекта, несет в себе и неблагоприятный результат, что порождает противоречие. Применение метода выявления противоречий позволило определить наличие положительных и нежелательных эффектов. Рассмотрены возможности снижения затрат на производство сдобных хлебобулочных изделий с использованием пароконвектомата на предприятиях социальной сферы (в школьных столовых).

\section{Abstract}

The application of functional and cost analysis (FCA) in machinery, instrumentation, power engineering and other industries shows the high efficiency: reducing of the production cost and articles number, simplifying of manufacturing technologies while maintaining the required quality level. FCA is particularly effective at the design stage of a new product, including foodstuff.

The authors investigated the possibility of FSA using aimed at cost reduction of the rich fermented bakery production of social nature, i.e. used for child feeding in a kindergarten and school. Thus, the product of daily consumption becomes more affordable for the consumer. The boundary conditions are the requirements of normative and technical 
documentation for the rich fermented bakery products; material and technical equipment and the enterprise production volume of social nature (school nutrition).

A typical analysis sequence takes into account character of the foodstuff production rich fermented bakery products.

The researchers ranked functions, described the ratio of "importance of costs" for each function.

In addition to the positive effect each accepted designed solution carries an unfavorable outcome raising a contradiction. Method application of making contradictions allowed to determine the positive and negative effects presence. The researchers considered the cost reduction possibility of rich fermented bakery production with the use of the convection steamer in the social sphere enterprises (in school canteens).

\section{Актуальность}

Перспективным направлением обеспечения качества товаров и услуг является использование на разных этапах проектирования и производства таких инструментов качества, как функционально-физический анализ (ФФА), функционально-стоимостной анализ (ФСА), FMEA-анализ (Failure Mode and Effects Analysis).

Метод ФСА, применяемый с целью снижения затрат, получил широкое распространение в различных областях жизнедеятельности человека: описаны методики проведения ФСА технических объектов на этапах проектирования, в том числе дляпоискановыхтехническихрешений;известно применение данного метода для сокращения издержек предприятий разного уровня - промышленных, административно-хозяйственных и др. Использование методики признано целесообразным при разработке пищевых продуктов (хотя до сих пор это не имеет широкого распространения [7]).

Функционально-стоимостной анализ - методология непрерывного совершенствования продукции, производственных технологий, организационных структур, целью которой является снижение всех видов затрат при одновременном сохранении или повышении качества. Основной принцип ФСА заключается в определении главных функций (тех, ради которых он и был создан), вспомогательных функций (без них невозможна реализация главной функции) и вредных функций объекта (излишние затраты, порожденные неправильным выбором или несовершенством конструкторских решений, либо возникшие в процессе реализации главной функции). Каждая функция может быть выполнена разными способами. Выбор способа закладывает и минимальную сумму затрат на создание функции, а заменив способ более дешевым, можно снизить затраты. Таким образом, ФСА представляет собой эффективный способ выявления резервов сокращения затрат, который основан на поиске более дешевых способов выполнения главных функций (путем организационных, технических, технологических и других изменений производства) при одновременном исключении лишних функций. Объектами ФСА могут быть как отдельные виды изделий, так и технологические процессы $[4 ; 8 ; 9 ; 10]$.

Поскольку объектом ФСА является пищевой продукт, то его главная функция - определение того, как продукт служит удовлетворению потребности в пище, в основных пищевых веществах и энергии; вспомогательная - выявление физико-химических, механических, эргономических особенностей продукта, обеспечивающих необходимую усвояемость (например, пористость хлебобулочных изделий, степень измельчения компонентов рубленых мясных изделий); вредная функция - определение того, что мешает полноценному усвоению продукта (наличие в составе продукта веществ, выступающих в роли ингибиторов, например авидино-биотиновый комплекс в сыром курином яйце), либо определение химически вредных для организма человека веществ, образовавшихся в процессе технологической обработки пищевого продукта.

Для ФСА пищевых продуктов характерны также дополнительные функции - определение наличия полезных биологически активных веществ (витаминов, микроэлементов). Эти функции целесообразно выделить в отдельную группу, характерную только для функциональных продуктов питания либо коммерчески ориентированных на повышенное содержание витаминов и минералов.

Использование ФСА для снижения затрат на производство пищевых продуктов возможно не только на этапе проектирования новых пищевых продуктов, но и для действующего производства, так как результаты анализа покажут слабые стороны его сырьевой и технологической составляющих. В хлебобулочных изделиях социального значения (например, используемых для питания детей в дошкольных и школьных учебных заведениях) особенно важно сохранять баланс качества изделия, требований норматив- 
но-технической документации и затрат на производство. Для этих целей в первую очередь подходит методика ФСА.

Этапы исследования

Проведение ФСА включает в себя ряд этапов: планирование, сбор информации, аналитический этап, поиск решений и формулирование рекомендаций [2; 6].

На этапе планирования выбирают объект, формулируют цель исследования, задающую граничные условия.

В качестве объекта данного исследования использовалась сдоба «Выборгская», входящая в ежедневный рацион питания школьников. Технология производства сдобы соответствует традиционной технологии производства сдобного дрожжевого теста безопарным способом.

Цель исследования - проведение комплексного анализа и поиск способов снижения затрат на производство сдобы «Выборгской».

В состав рабочей группы входили специалисты и консультанты кафедр Кемеровского технологического института пищевой промышленности (университета).

В прочессе сбора информации были проанализированы нормативные и технические документы, регламентирующие качество и безопасность сдобы «Выборгской»:
-ГОСТ 24557-89. Изделия хлебобулочные сдобные. Технические условия (с Изменением № 1);

- ГОСТ 24298-80. Изделия хлебобулочные мелкоштучные. общие технические условия (с Изменениями № 1, 2);

-ГОСТ 32677-2014. Изделия хлебобулочные. Термины и определения (с Поправкой);

- ГОСТ 31805-2012. Изделия хлебобулочные из пшеничной муки. Общие технические условия: Технико-технологическая карта «Булочка "Выборгская"», предоставленная МБУ «Комбинат питания", применяемая в школах, работающих по программе «Здоровое питание Кузбасса».

Была составлена калькуляционная карта на рецептуру сдобы.

Собранные основные данные о продукте (сырьевая и технологическая составляющие) представлены в табл. 1.

Аналитический этап - определение перечня функций и значимости каждой при традиционном производстве сдобных хлебобулочных изделий. В данном случае рассмотрены сырьевая и технологическая функции.

Особенность данного этапа заключается в том, что значимость функции можно определять с использованием комплекса критериев, учитывающих специфику пищевой промышленности.

\section{таблица 1}

Сдоба «Выборгская»: основные данные для проведения ФСА

\begin{tabular}{|r|l|c|c|}
\hline № & Технологическая операция & Сырье & $\begin{array}{c}\text { Стоимость сырья } \\
\text { на единицу } \\
\text { продукции, р. }\end{array}$ \\
\hline 1. & Нагревание, $\mathrm{T}=38^{\circ} \mathrm{C}$ & Мука пшеничная «Беляевская» (высший сорт) & 0,59 \\
\hline 2. & Нагревание, $\mathrm{T}=100^{\circ} \mathrm{C}$ & Масло сливочное & 0,42 \\
\hline 3. & Просеивание & Сахар-песок & 0,30 \\
\hline 4. & Обработка & Дрожжи прессованные & 0,02 \\
\hline 5. & Перемешивание & Соль & 0,04 \\
\hline 6. & Замешивание & Вода & 0,15 \\
\hline 7. & Брожение & 0,02 \\
\hline 8. & Обминка & Масло растительное для смазки листов & 0,54 \\
\hline 9. & Брожение & Яйцо для смазки & - \\
\hline 10. & Обминка & - & - \\
\hline 11. & Формование & - & - \\
\hline 12. & Расстойка & - & - \\
\hline 13. & Смазка поверхности & - & - \\
\hline 14. & Расстойка & - & - \\
\hline 15. & Выпечка & - & - \\
\hline 16. & Охлаждение & - & - \\
\hline
\end{tabular}


Для сырьевой составляющей и технологического процесса производства продукта питания использовались следующие группы критериев:

-1-я группа критериев (применимы к сырьевой составляющей): доступность, взаимозаменяемость, качество;

- 2-я группа критериев (применимы к технологии производства): целесообразность, надежность, экономичность (малоотходность).

С учетом указанных критериев максимальный показатель значимости - 9 баллов - присваивается при условии, что функция максимально соответствует критерию (каждый критерий максимально оценивался тремя баллами: 0 - совершенно не соответствует критерию; 1 балл - отчасти соответствует критерию; 2 балла - скорее соответствует, чем нет; 3 балла - полностью соответствует критерию).

Аналитический этап включает в себя:

1) составление функциональной структуры и ранжирование функций (осуществляются одно- временно для сырьевой составляющей и для технологии производства). При этом необходимо определить вид каждой функции;

2) определение затрат для каждой функции на основе информационных данных (включая сырьевую составляющую и технологию производства);

3) определение значимости каждой функции по двум группам вышеописанных критериев;

4) выявление неблагополучных функций в процессе сопоставления "значимость - затраты» и дальнейшего их анализа.

Функции сырьевой и технологической составляющих авторы определяли исходя из значимости баллов, используемых при оценке экспертной комиссией, в которую вошли представители рабочей группы. Оценка проводилась по 10-балльной шкале [3].

Пример аналитического этапа ФСА применительно к сдобе «Выборгской» представлен ниже (табл. 2).

Таблица 2

Соотношение «значимость - затраты» как результат аналитического этапа ФСА

\begin{tabular}{|c|c|c|c|c|c|}
\hline $\begin{array}{c}\text { № } \\
\text { функции }\end{array}$ & Компонента & Функция & $\begin{array}{c}\text { Значимость }(\mathrm{Hi}), \\
\text { баллов }\end{array}$ & $\begin{array}{c}\text { Затраты (Zi), } \\
\text { баллов }\end{array}$ & $\begin{array}{c}\text { Соотношение } \\
\text { Zi/ Hi }\end{array}$ \\
\hline \multicolumn{6}{|c|}{ Сырьевая составляющая } \\
\hline 1 & Мука & Главная & 9 & 10 & 1,11 \\
\hline 2 & Дрожжи прессованные & Дополнительная & 6 & 2 & 0,30 \\
\hline 3 & Яйцо куриное & Вспомогательная & 7 & 10 & 1,43 \\
\hline 4 & Вода питьевая & Вспомогательная & 4 & 2 & 0,50 \\
\hline 5 & Масло сливочное & Вспомогательная & 4 & 7 & 1,75 \\
\hline 6 & Caxap & Вспомогательная & 6 & 5 & 0,83 \\
\hline 7 & Соль & Вспомогательная & 5 & 2 & 0,40 \\
\hline \multicolumn{6}{|c|}{ Технологическая составляющая } \\
\hline 8 & Нагревание, $\mathrm{T}=(35-38){ }^{\circ} \mathrm{C}$ & Вспомогательная & 9 & 3 & 0,33 \\
\hline 9 & Нагревание, $\mathrm{T}=(35-40){ }^{\circ} \mathrm{C}$ & Вспомогательная & 5 & 5 & 1,00 \\
\hline 10 & Просеивание & Вспомогательная & 7 & 5 & 1,40 \\
\hline 11 & Обработка & Вредная & 9 & 7 & 0,78 \\
\hline 12 & Процеживание & Вспомогательная & 8 & 3 & 0,38 \\
\hline 13 & Перемешивание & Вспомогательная & 8 & 5 & 0,63 \\
\hline 14 & Замешивание & Главная & 8 & 5 & 0,63 \\
\hline 15 & Брожение & Главная & 6 & 10 & 1,67 \\
\hline 16 & Обминка & Вспомогательная & 6 & 9 & 1,50 \\
\hline 17 & Разделка & Вспомогательная & 8 & 10 & 1,25 \\
\hline 18 & Формование & Вспомогательная & 6 & 10 & 1,67 \\
\hline 19 & Смазка поверхности & Вспомогательная & 6 & 9 & 1,50 \\
\hline 20 & Расстойка & Вспомогательная & 7 & 8 & 1,14 \\
\hline
\end{tabular}




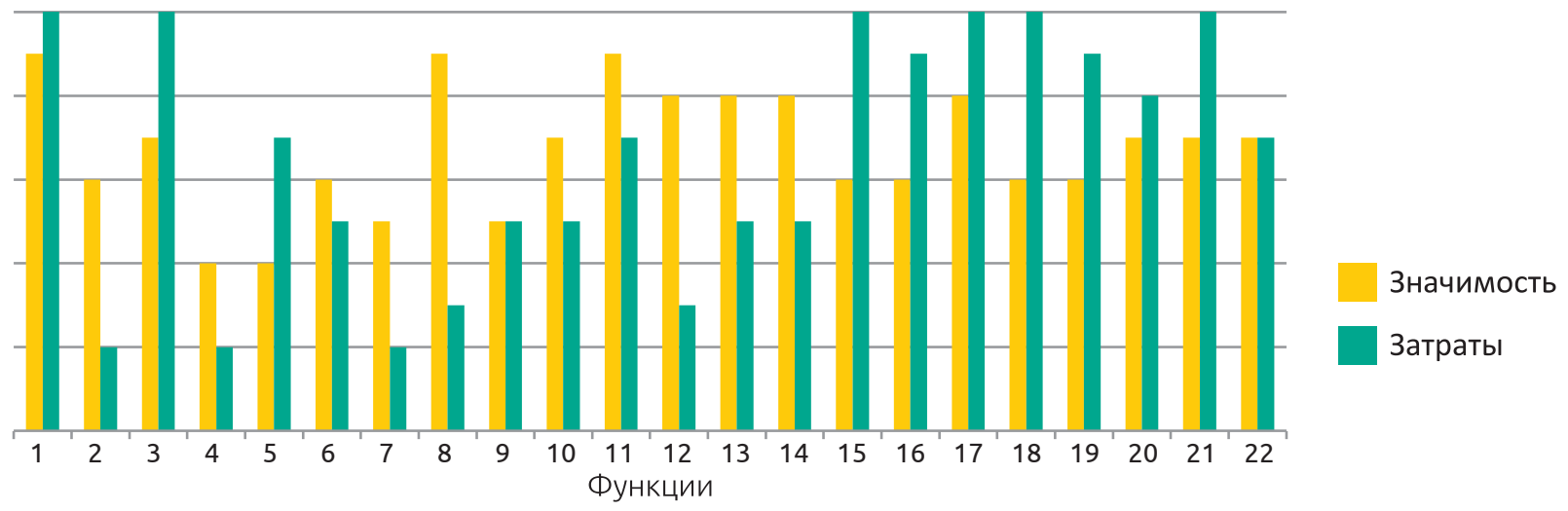

Puc. 1. Сопоставление «значимость - затраты» при производстве сдобныххлебобулочных изделий

На основании таблицы была построена диаграмма сопоставления "значимость - затраты", которая наглядно показала «проблемные» функции сырьевой и технологической составляющей производства сдобных хлебобулочных изделий традиционным способом. Диаграмма сопоставления представлена на рис. 1.

Согласно диаграмме 10 из 22 функций (в частности, три сырьевых и семь технологических) являются неблагоприятными, т. е. затраты на реализацию существенно превышают их значимость; функции 9-я и 22-я имеют равные показатели значимости и затрат и могут быть рассмотрены в ходе анализа. Перечень неблагоприятных функций представлен ниже (табл. 3).

Поиск решений и формулирование рекомендаций. После выявления неблагоприятных функций разрабатывались меры по разрешению противоречий. Рабочей группой были приняты соответствующие решения (для наглядности сгруппированы в табл. 4).
Таблица 3

Перечень неблагоприятных функций при производстве сдобных хлебобулочных изделий

\begin{tabular}{|c|c|c|}
\hline $\begin{array}{c}\text { № } \\
\text { функции }\end{array}$ & Компонента & $\begin{array}{c}\text { Соотношение } \\
\text { Zi / Hi }\end{array}$ \\
\hline \multicolumn{3}{|c|}{ Сырьевая составляющая } \\
\hline 1 & Мука & 1,11 \\
\hline 3 & Яйцо куриное & 1,43 \\
\hline 5 & Масло сливочное & 1,75 \\
\hline \multicolumn{3}{|c|}{ Технологическая составляющая } \\
\hline 15 & Брожение & 1,67 \\
\hline 16 & Обминка & 1,50 \\
\hline 17 & Разделка & 1,25 \\
\hline 18 & Формование & 1,67 \\
\hline 19 & Смазка поверхности & 1,50 \\
\hline 20 & Расстойка & 1,14 \\
\hline 21 & Выпечка & 1,43 \\
\hline
\end{tabular}

таблица 4

Комплекс мер по разрешению противоречий

\begin{tabular}{|c|c|c|}
\hline $\begin{array}{c}\text { № } \\
\text { функции }\end{array}$ & Компонента & Решение \\
\hline 3 & Яйцо куриное & Заменить льезоном; не смазывать поверхность тестового полуфабриката \\
\hline 5 & Масло сливочное & Заменить более дешевым ингредиентом, маргарином \\
\hline 15 & Брожение & $\begin{array}{l}\text { 1. Сокращение времени брожения за счет использования } \\
\text { быстродействующих дрожжей. } \\
\text { 2. Увеличение количества используемых дрожжей. } \\
\text { 3. Оптимизация параметров (режим «расстойка» в пароконвектомате, } \\
\text { расстоечном шкафу UNOX) }\end{array}$ \\
\hline 16 & Обминка & Нет решения \\
\hline 17 & Разделка & Использование тесторазделительных и тестоокруглительных машин \\
\hline 18 & Формование & Более простая форма \\
\hline 19 & Смазка поверхности & Не смазывать поверхность \\
\hline 20 & Расстойка & $\begin{array}{l}\text { Отработка режимов расстойки в расстоечном шкафу при температуре } \\
\text { до } 70^{\circ} \mathrm{C} \text { и пароконвектомате }\end{array}$ \\
\hline 21 & Выпечка & $\begin{array}{l}\text { Подбор оптимальных параметров выпечки на современном } \\
\text { оборудовании для предприятий общественного питания }\end{array}$ \\
\hline
\end{tabular}


Результаты исследований и рекомендации

После принятия решений были оформлены рекомендации по их реализации. В представленном примере все противоречия (кроме 16-й функции) были разрешены.

Для 21-й функции был проведен подбор оптимальных параметров выпечки в пароконвектомате с целью уменьшения упёка и сокращения времени выпечки. При отработке режимов и параметров выпечки сдобных хлебобулочных изделий в пароконвектомате были выявлены как положительные, так и нежелательные эффекты процесса.

Сравнительный анализ параметров выпечки сдобы «Выборгской» в конвекционной печи и в пароконвектомате представлен в табл. 5.
Использование пароконвектомата для выпечки сдобных хлебобулочных изделий признано целесообразным, так как снижается упёк и сокращается время выпечки изделия. Вместе с тем сохраняется нежелательный эффект выпечки сдобы при заявленных условиях, а именно неравномерность окраски поверхности готового изделия [1].

При увеличении времени выпечки с 8 до 10 мин окраска становится более интенсивной и равномерной, однако упёк в этом случае составляет 12,5 \%. Особенности выпечки сдобы «Выборгской» в пароконвектомате были представлены в форме противоречия (рис. 2) [5]. За параметр $X$ приняли время нахождения тестовых заготовок в камере пароконвектомата.

таблица 5

Параметры выпечки сдобы «Выборгской» в конвекционной печи и пароконвектомате

\begin{tabular}{|c|c|c|}
\hline Параметр & Конвекционная печь & Пароконвектомат \\
\hline Температура, ${ }^{\circ} \mathrm{C}$ & 180 & 180 \\
\hline Влажность в рабочей камере, \% & Регулируется вручную & 10 \\
\hline Скорость вращения вентилятора & Не регулируется & $1 / 2$ \\
\hline Время выпечки, мин & 12 & 8 \\
\hline Упёк, \% & 14 & 10,2 \\
\hline
\end{tabular}
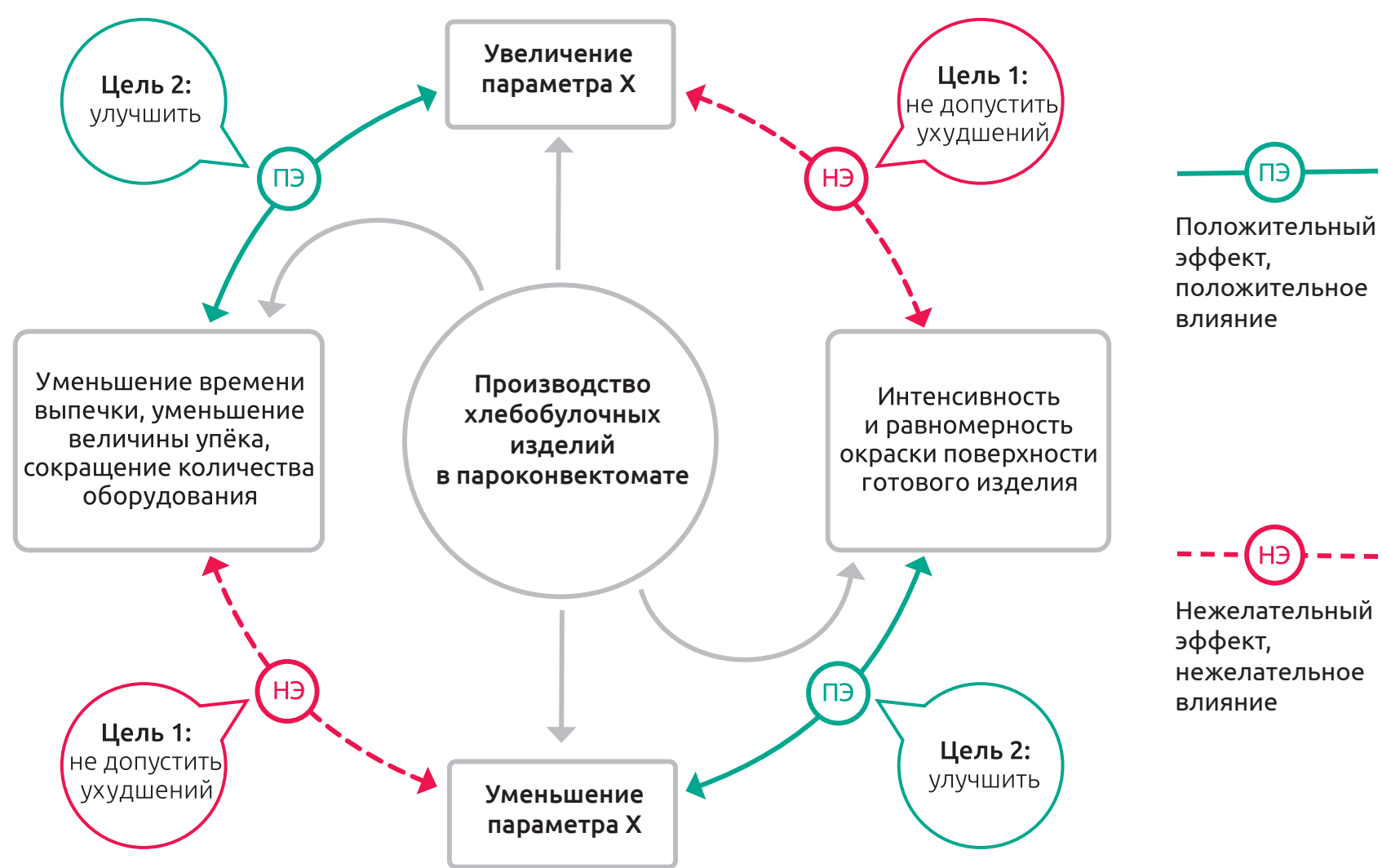

Положительный эффект, положительное влияние

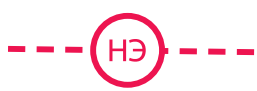

Нежелательный эффект, нежелательное влияние

Puc. 2. Схема противоречия на примере выпечки сдобы в пароконвектомате 
Таблица 6

Режимы и параметры брожения теста в пароконвектомате
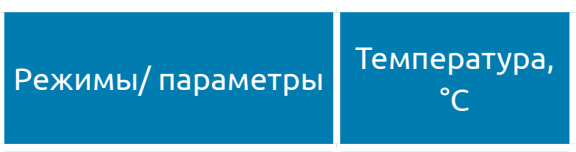

Автоматический режим «расстойка»

Ручной режим

Ручной режим

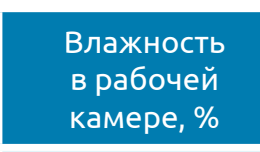

32

35

35
Не указана производителем

50 50

Время
брожения,
мин

60 50 60

\section{Скорость}

вращения

вентилятора

Импульс-режим

$1 / 2$

Импуль-режим

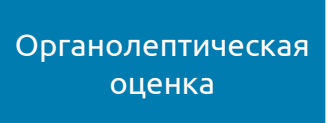

За время брожения тесто увеличивается в объеме в 2 раза, поверхность не заветривается
Таким образом, чем короче время выпечки тестовых заготовок, тем бледнее и менее равномерно окрашена их поверхность, но меньше величина упёка, и наоборот - чем дольше выпекаются тестовые заготовки в пароконвектомате, тем больше упёк, равномернее и интенсивнее колер поверхности.

В ходе эксперимента была рассмотрена возможность использования пароконвектомата для технологических операций брожения теста и расстойки тестовых заготовок. Проведено исследование стандартного режима расстойки пароконвектомата и режима ручного ввода параметров, подходящих для данного технологического этапа. Данные представлены в табл. 6.

Оптимальным признан автоматический режим пароконвектомата «расстойка», однако в случае отсутствия автоматического режима можно использовать пароконвектомат для брожения теста при следующих параметрах: температура - $35^{\circ} \mathrm{C}$; влажность в рабочей камере - 50 \%; скорость вращения вентилятора - импульс-режим.

Сформулированные противоречия позволяют наметить локальные задачи по их устранению, т. е. была поставлена задача устранить нежелательные эффекты, сохранив положительные. Для ее реализации определена область поиска возможных решений, сформулированы частные задачи. Нежелательные эффекты использования пароконвектомата для полного цикла производства сдобных хлебобулочных изделий на примере сдобы «Выборгской» и варианты разрешения противоречий сведены (для наглядности) в табл. 7.

Выводы

Применение метода функционально-стоимостного анализа позволило выявить наиболее затратные функции производства сдобы «Выборгской» на предприятиях социальной сферы и принять решения по снижению затрат на изготовление данного хлебобулочного изделия.

Метод выявления противоречий показал зависимость положительных и нежелательных эффектов принятых решений. Показана возможность снижения затрат на производство сдобы «Выборгской» с использованием пароконвектомата.

\section{Таблица 7}

Частные задачи устранения нежелательных эффектов и возможные варианты их решения

\section{Частные задачи}

1. Сокращение загрузки пароконвектомата

2. Устранение необходимости вынимать тестовые заготовки из рабочей камеры перед выпечкой

3. Неравномерность окраски поверхности готового х/6 продукта

\section{Возможные решения}

1. Проведение брожения и расстойки при нормальных условиях (комнатная температура).

2. Использование дополнительного оборудования (расстоечный шкаф)

1. Отработка «безвыемного» способа выпечки изделий.

2. Определение ассортимента изделий, на качество которых не влияет выпечка «безвыемным» способом

1. Определение ассортимента хлебобулочной продукции, для которой бледность или неравномерность колера поверхности не ухудшает потребительские свойства.

2. Отделка поверхности изделий.

3. Создание равномерного колера (например, изменение скорости и направления движения воздуха в рабочей камере).

4. Поиск оборудования с максимально равномерной циркуляцией воздуха.

5. Использование изделий со слабым колером в детском, диетическом и лечебном питании 


\section{Библиографический список}

1. Давыденко Н.И., Уржумова А.И., Шевелева Г.И., Григорьева Р.3. Влияние режимов и параметров выпечки в пароконвектомате на качество сдобных булочных изделий // Техника и технология пищевых производств. 2017. Т. 44. № 1. С. 11-16.

2. Кузьмина О.Н. Функционально-стоимостной анализ: методические подходы и концептуальные основы // Вестник Самарского государственного экономического университета. 2014. № 6 (116). С. 121-125.

3. Майоров А.А., Сурай Н.М. Применение метода экспертных оценок при формировании ассортимента молочной продукции // Вестник Омского государственного аграрного университета. 2014. № 1. С. 77-81.

4. Мезенцев Ю.А., Преображенская Т.В. Функционально-стоимостный анализ. Инструменты и модели: учеб. пособие. Новосибирск : [6. и.], 2003. 122 с.

5. Методические указания по выполнению семинара 4 по единому комплексному заданию по блоку дисциплин «Защита интеллектуальной собственности» / кол. авт. М.: МГТУ им. Н.Э. Баумана, 2012. 24 c.

6. Мясоедова Л.В., Хабибуллина Е.Р. Функционально-стоимостной анализ как инстумент инженерного маркетинга // Вестник Донского государственного технического университета. 2010. Т. 10. № 4 (47). С. 583-588.

7. Новоселов С.В., Маюрникова Л.А., Ремизов С.В., Руднев С.Д. Анализ перспектив инновационной деятельности на стадии проектирования пищевых продуктов // Ползуновский вестник. 2013. № 4-4. C. 33-43.

8. Половинкин А.И. Основы инженерного творчества: уче6. посо6ие. СПб.: Лань, 2007. 368 с.

9. Ревенков А.В., Резчикова Е.В. Теория и практика решения технических задач: учеб. пособие. 2-е изд., испр. и доп. М. : ФОРуМ, 2009. 384 c.

10. Шпаковский Н.А. ТРИЗ. Анализ технической информации и генерация новых идей: учеб. пособие. М.: Форум, 2010. 264 с.

\section{Bibliography}

1. Davydenko N.I., Urzhumova A.I., Sheveleva G.I., Grigor'eva R.Z. Vlijanie rezhimov i parametrov vypechki v parokonvektomate na kachestvo sdobnyh bulochnyh izdelij // Tehnika i tehnologija pishhevyh proizvodstv. 2017. T. 44. № 1. S. 11-16.

2. Kuz'mina 0.N. Funkcional'no-stoimostnoj analiz: metodicheskie podhody i konceptual'nye osnovy // Vestnik Samarskogo gosudarstvennogo jekonomicheskogo universiteta. 2014. № 6 (116). S. $121-125$.

3. Majorov A.A., Suraj N.M. Primenenie metoda jekspertnyh ocenok pri formirovanii assortimenta molochnoj produkcii // Vestnik Omskogo gosudarstvennogo agrarnogo universiteta. 2014. № 1. S. 77-81.

4. Mezencev Ju.A., Preobrazhenskaja T.V. Funkcional'no-stoimostnyj analiz. Instrumenty i modeli: ucheb. posobie. Novosibirsk : [b. i.], 2003. $122 \mathrm{~s}$.

5. Metodicheskie ukazanija po vypolneniju seminara 4 po edinomu kompleksnomu zadaniju po bloku disciplin «Zashhita intellektual'noj sobstvennosti»/ kol. avt. M.: MGTU im. N.Je. Baumana, 2012. $24 \mathrm{~s}$.

6. Mjasoedova L.V., Habibullina E.R. Funkcional'no-stoimostnoj analiz kak instument inzhenernogo marketinga // Vestnik Donskogo gosudarstvennogo tehnicheskogo universiteta. 2010. T. 10. № 4 (47). S. 583-588.

7. Novoselov S.V., Majurnikova L.A., Remizov S.V., Rudnev S.D. Analiz perspektiv innovacionnoj dejatel'nosti na stadii proektirovanija pishhevyh produktov // Polzunovskij vestnik. 2013. № 4-4. S. 33-43.

8. Polovinkin A.I. Osnovy inzhenernogo tvorchestva: ucheb. posobie. SPb.: Lan', 2007. $368 \mathrm{~s}$.

9. Revenkov A.V., Rezchikova E.V. Teorija i praktika reshenija tehnicheskih zadach: ucheb. posobie. 2-e izd., ispr. i dop. M. : FORUM, 2009. $384 \mathrm{~s}$.

10. Shpakovskij N.A. TRIZ. Analiz tehnicheskoj informacii i generacija novyh idej: ucheb. posobie. M.: Forum, 2010.264 s.

\section{Маюрникова \\ Лариса Александровна}

Majurnikova

Larisa Aleksandrovna

Тел./Phone: (3842) 39-68-56

E-mail:Nir30@mail.ru

\section{Уржумова}

\section{Анна Игоревна}

Urzhumova

Anna Igorevna

тел./Phone: (3842) 39-68-56

E-mail:sershih@rambler.ru

\section{Клишина}

Мария Николаевна

Klishina

Mariya Nikolaevna

тел./Phone: (3842) 39-68-56 E-mail: Nir30@mail.ru
Доктор технических наук, профессор, заведующий кафедрой технологии и организации общественного питания Кемеровский технологический институт пищевой промышленности (университет) 650056, РФ, г. Кемерово, бульвар Строителей, 47

Doctor of Technical Science, Professor, Head of the Catering Technology and Arrangement Department

Kemerovo Institute of Food Science and Technology 650056, Russia, Kemerovo, Stroiteley Blvd, 47

Аспирант кафедры технологии и организации общественного питания Кемеровский технологический институт пищевой промышленности (университет) 650056, РФ, г. Кемерово, бульвар Строителей, 47

Post-graduate of the Catering Technology and Arrangement Department Kemerovo Institute of Food Science and Technology 650056, Russia, Kemerovo, Stroiteley Blvd, 47

Аспирант кафедры технологии и организации общественного питания Кемеровский технологический институт пищевой промышленности (университет) 650056, РФ, г. Кемерово, бульвар Строителей, 47

Post-graduate of the Catering Technology and Arrangement Department Kemerovo Institute of Food Science and Technology 650056, Russia, Kemerovo, Stroiteley Blvd, 47 